\title{
Persistent mosquito fogging is detrimental to non-target invertebrates in an urban tropical forest
}

\author{
Nicole SM Lee ${ }^{\text {Corresp., } 1}$, Gopalasamy R Clements ${ }^{2}$, Adeline SY Ting ${ }^{1}$, Zhi H Wong $^{3}$, Sze H Yek ${ }^{\text {Corresp. } 1}$ \\ ${ }^{1}$ School of Science, Monash University Malaysia, Bandar Sunway, Selangor, Malaysia \\ Department of Biological Sciences and Jeffrey Sachs on Sustainable Development, Sunway University, Bandar Sunway, Selangor, Malaysia \\ 3 Malaysia Immersion Hub, Monash University Malaysia, Bandar Sunway, Selangor, Malaysia \\ Corresponding Authors: Nicole SM Lee, Sze H Yek \\ Email address: nlee0010@student.monash.edu, yek.szehuei@monash.edu
}

Background: Human population growth has led to biodiversity declines in tropical cities. While habitat loss and fragmentation have been the main drivers of urban biodiversity loss, man-made interventions to reduce health risks have also emerged as an unintentional threat. For instance, insecticide fogging to control mosquito populations has become the most common method of preventing the expansion of mosquito-borne diseases such as Dengue. However, the effectiveness of fogging in killing mosquitoes has been called into question. One concern is the unintended effect of insecticide fogging on non-target invertebrates that are crucial for the maintenance of urban ecosystems. Here, we investigate the impacts of fogging on: 1) target invertebrate taxon (Diptera, including mosquitoes); 2) non-target invertebrate taxa; and 3) the foraging behavior of an invertebrate pollinator taxon (Lepidoptera) within an urban tropical forest.

Methods: We carried out fogging with Pyrethroid insecticide (Detral $2.5 \mathrm{EC}$ ) at 10 different sites in a forest situated in the state of Selangor, Peninsular Malaysia. Across the sites, we counted the numbers of knocked-down invertebrates and identified them based on morphology to different taxa. We constructed Bayesian Hierarchical Poisson regression models to investigate the effects of fogging on: 1) a target invertebrate taxon (Diptera) 3-hr post-fogging; 2) selected non-target invertebrate taxa 3-hr postfogging; and 3) an invertebrate pollinator taxon (Lepidoptera) 24-hr post-fogging.

Results: A total of 1874 invertebrates from 19 invertebrate orders were knocked down by fogging treatment across the 10 sites. Furthermore, $72.7 \%$ of the invertebrates counted 3-hr post-fogging was considered dead. Our regression models showed that given the data and prior information, the probability that fogging had a negative effect on invertebrate taxa 3-hr post-fogging was $100 \%$, with reductions to $11 \%$ of the pre-fogging count of live individuals for the target invertebrate taxon (Diptera), and between $5 \%$ to $58 \%$ of the pre-fogging count of live individuals for non-target invertebrate taxa. For the invertebrate pollinator, the probability that fogging had a negative effect 24-hr post-fogging was also $100 \%$, with reductions to $53 \%$ of the pre-fogging count of live individuals.

Discussion: Our Bayesian models unequivocally demonstrate that fogging has detrimental effects on one pollinator species and non-target invertebrate orders, especially taxa that have comparatively lower levels of chitinisation. While fogging is effective in killing the target order (Diptera), no mosquitos were found dead in our experiment. In order to maintain urban biodiversity, we recommend that health authorities and the private sector move away from insecticide fogging and to explore alternative measures to control adult mosquito populations. 


\section{Persistent mosquito fogging is detrimental to non-target \\ 2 invertebrates in an urban tropical forest}

3 Nicole Sze Mei Lee ${ }^{1}$, Gopalasamy Reuben Clements ${ }^{2}$, Adeline Su Yien Ting ${ }^{1}$, Zhi Hoong

4 Wong $^{3}$, Sze Huei Yek ${ }^{1}$

5

$6 \quad{ }^{1}$ School of Science, Monash University Malaysia, Bandar Sunway, Selangor, Malaysia

$7 \quad{ }^{2}$ Department of Biological Sciences and Jeffrey Sachs on Sustainable Development, Sunway

8 University, Bandar Sunway, Selangor, Malaysia

$9{ }^{3}$ Malaysian Immersion Hub, Monash University Malaysia, Bandar Sunway, Selangor, Malaysia

12 Corresponding Authors:

13 Sze Huei Yek ${ }^{1}$

14 Email address: yek.szehuei@monash.edu

15 Nicole Sze Mei Lee ${ }^{1}$

16 Email address: nlee0010@student.monash.edu 


\section{Abstract}

24 Background: Human population growth has led to biodiversity declines in tropical cities. While 25 habitat loss and fragmentation have been the main drivers of urban biodiversity loss, man-made interventions to reduce health risks have also emerged as an unintentional threat. For instance, insecticide fogging to control mosquito populations has become the most common method of preventing the expansion of mosquito-borne diseases such as Dengue. However, the effectiveness of fogging in killing mosquitoes has been called into question. One concern is the unintended effect of insecticide fogging on non-target invertebrates that are crucial for the maintenance of urban ecosystems. Here, we investigate the impacts of fogging on: 1) target invertebrate taxon (Diptera, including mosquitoes); 2) non-target invertebrate taxa; and 3) the foraging behavior of an invertebrate pollinator taxon (Lepidoptera) within an urban tropical 34 forest.

Methods: We carried out fogging with Pyrethroid insecticide (Detral 2.5 EC) at 10 different sites in a forest situated in the state of Selangor, Peninsular Malaysia. Across the sites, we counted the numbers of knocked-down invertebrates and identified them based on morphology to different taxa. We constructed Bayesian Hierarchical Poisson regression models to investigate the effects of fogging on: 1) a target invertebrate taxon (Diptera) 3-hr post-fogging; 2) selected non-target invertebrate taxa 3-hr post-fogging; and 3) an invertebrate pollinator taxon

42 (Lepidoptera) 24-hr post-fogging.

Results: A total of 1874 invertebrates from 19 invertebrate orders were knocked down by fogging treatment across the 10 sites. Furthermore, $72.7 \%$ of the invertebrates counted 3-hr postfogging was considered dead. Our regression models showed that given the data and prior information, the probability that fogging had a negative effect on invertebrate taxa 3-hr postfogging was $100 \%$, with reductions to $11 \%$ of the pre-fogging count of live individuals for the target invertebrate taxon (Diptera), and between $5 \%$ to $58 \%$ of the pre-fogging count of live individuals for non-target invertebrate taxa. For the invertebrate pollinator, the probability that 
54 Discussion: Our Bayesian models unequivocally demonstrate that fogging has detrimental 55 effects on one pollinator species and non-target invertebrate orders, especially taxa that have 56 comparatively lower levels of chitinisation. While fogging is effective in killing the target order 57 (Diptera), no mosquitos were found dead in our experiment. In order to maintain urban 58 biodiversity, we recommend that health authorities and the private sector move away from 59 insecticide fogging and to explore alternative measures to control adult mosquito populations. 
60

61 Urban biodiversity is expected to decline under current human population growth rates. More

\section{Introduction}

63

64

65

66

67

68

69

70

71

72

73

74 than half of the world's population now resides in cities (Zhang 2016) - this is likely to lead to massive land development and consequently, greater rates of natural habitat loss and fragmentation (Clark, Reed \& Chew, 2007). While urbanization has led to the decline of certain invertebrate taxa (Eisenhauer, Bonn \& Guerra, 2019), it has resulted in an increase in incidences of vector-borne diseases such as Dengue fever and Malaria, especially in areas with poor planning and management practices (Knudsen \& Slooff, 1992). Vector-borne diseases make up more than $17 \%$ of all infectious diseases and results in over one million deaths a year (World Health Organization [WHO], 2017). In particular, diseases spread by the Aedes spp. mosquitoes such as Dengue, Chikungunya and Zika pose a serious health risk in cities due to the mosquito's affinity towards urban areas (Koou et al., 2014). Urbanization inevitably results in more breeding sites for these mosquitoes as stagnant water sources increase due to improper waste disposal practices, open trash cans, and poor surface-water drainage (Lee et al., 2019).

Malaysia is on the list of countries that have high incidences of Dengue outbreaks, with Dengue cases gradually increasing over the years (European Centre for Disease Prevention and Control, 2019). With limited vaccines available to minimise the spread of vector-borne diseases, prevention and control continue to be the main mitigation strategies (Benelli, Jeffries \& Walker, 2016; Fournet et al., 2018). For mosquito-borne diseases, there are three main approaches: 1) chemical control that involves fogging (i.e. insecticide spraying) to kill adult mosquitos (Usuga et al., 2019); 2) biological control that uses natural predators of mosquito larvae; and 3) environmental management and integrated vector management to reduce the mosquito breeding grounds (Amal et al., 2011). Of these methods, fogging is the most common form of adult mosquito population control in Malaysia, and is mainly carried out by both the Ministry of Health and the private sector in urban areas that experience vector-borne disease outbreaks (Amin et al., 2019).

Studies examining the efficiency of fogging in controlling adult mosquito populations have yielded mixed results. Some demonstrate short-lived effective mosquito population control (Amal et al., 2011), but others show evidence of mosquito populations developing increasing resistance towards commonly used fogging insecticides (Marcombe et al., 2011; Shafie, Tahir, \& 
90 Sabri, 2012). The long-term cost of mosquito developing resistance to insecticides outweighs the

91 benefits of temporary reductions in adult populations, especially when new reports of Dengue

92 regularly emerge in recently treated areas (Usuga et al., 2019).

93 A major source of concern for urban biodiversity is that sanctioned insecticides used in 94 fogging is not explicitly selective towards mosquitoes - this poses a serious threat to non-target 95 invertebrate communities that share the same habitats as mosquitoes (Braak et al., 2018). For 96 example, studies have shown that natural insecticides such as pyrethrins can kill a wide range of 97 insects but are ineffective at killing its targeted species - mosquitoes (Kwan et al., 2009; 98 Abeyasuriya et al., 2017). As such, more studies are needed to understand how fogging affects 99 non-target invertebrates in the urban environment.

100 Here, we investigate the impact of mosquito fogging on: 1) its target invertebrate taxon 101 (Diptera); 2) selected non-target invertebrate taxa; and 3) the foraging behavior of an 102 invertebrate pollinator taxon (Lepidoptera) within an urban tropical forest.

\section{Materials \& Methods}

\section{Study area}

106 Our study was conducted in Kota Damansara Community Forest (KDCF) $\left(3.17^{\circ} \mathrm{N}, 101.58^{\circ} \mathrm{E}\right)$, a 107 secondary forest located in Selangor, one of the most urbanized states in Malaysia (Yaakob, 108 Masron \& Masami, 2012). The forest is under the management of Forestry Department Malaysia 109 (permit number for this experiment: PHD.ST.052/2019) and has a diverse invertebrate 110 community. Over 13 different insect orders, mainly Coleoptera, Hymenoptera and Diptera were 111 collected in a previous study (Khadijah, Azizah \& Meor, 2013). As of September 2019, Selangor

112 was the state with the highest reported cases of Dengue and Chikngunya disease in Malaysia

113 (European Centre for Disease Prevention and Control, 2019). While the interior of KDCF is not 114 fogged, its surrounding suburban areas are constantly fogged, making KDCF an ideal study site 115 to examine the indirect effect of fogging on urban invertebrate (Fig. 1). 
118 The entrance to KDCF (filled circle) is surrounded by a government school - SMK Seksyen 10

119 Kota Damansara (dark grey square), the high rise condominium - De Rozelle (dark grey

120 triangle). KDCF experiences regular fogging by different private companies in an effort to

121 control vector-borne mosquito diseases (Kota Damansara residents, 2019, pers. comm.). Image

122 credit: OpenClipart at https://freesvg.org/.

123 Tree's within KDCF primarily consist of secondary species such as Alstonia scholarisa and

124 Macaranga spp., however, some primary species such as Shorea platyclados has also been

125 observed in its premises (Salleh, 2006). Ten trees within the KDCF compound were chosen for

126 fogging treatments (Supplementary Table 1). The criteria for these trees are: (1) each tree is at

127 least $100 \mathrm{~m}$ away from each other to prevent fogging overlap; (2) each tree is within the height

128 range of $3 \mathrm{~m}$ for standardized vertical fogging dispersion; (3) each tree has an umbrella-like

129 canopy cover with less than $10 \%$ herbivory damage on the canopy leaves for standardized

130 horizontal surface area exposed to fogging; and (4) each tree is within $1 \mathrm{~km}$ away from the

131 hiking trail as mosquitos tend so seek human hosts around hiking trails. Thus, it is likely that the

132 chosen trees were subcanopy species.

133

\section{Fogging treatments}

135 Insecticide fogging was carried out twice a week at $1100 \mathrm{~h}$ for a total of five weeks in the months

136 of August to September 2019. The fogging time for mosquito control should ideally be around

137 dawn or dusk for most effective mosquito control (Amal et al. 2011). However, for the purpose

138 of our experiment, we choose $1100 \mathrm{~h}$ as these are the times where most hikers are not using the

139 KDCF trails and pollinators are most active. Nevertheless, we assumed that mosquitoes would be

140 present in the canopy regardless of our fogging time based on a recent study conducted in KDCF

141 (Lee et al., 2019). Professional fogging personnel from Ridpest Sdn Bhd

142 (https://www.ridpest.com/) were employed to carry out the fogging experiment using a hand held

143 pulse thermal fog generator (Fig. 2a). The Detral 2.5 EC insecticide brand, which consisted of

144 the active ingredient deltamethrin $2.5 \% \mathrm{w} / \mathrm{w}$, was utilized for the fogging treatment (Fig. 2b).

145 Deltamethrin is a synthetic pyrethroid commonly used for mosquito fogging that targets the

146 nervous system of invertebrates (Chrustek et al., 2018). This insecticide solution was prepared to

147 the specified dosage (1:200 ratio of insecticide to water) according to instructions on the bottle 
148 label, used for normal fogging around residential areas. The licensed foggers would fog the tree

149 starting at the bottom, thus allowing the fog to disperse to the top of the canopy (Fig. 2a). Each

150 tree was fogged for 10 minutes, which is the minimum standard duration set by the Ministry of

151 Health (http://www.moh.gov.my/). The standard duration for fogging is between 10 to $15 \mathrm{~min}$

152 depending on the severity of the mosquito-borne diseases reported and land area intended to be

153 covered. For this experiment, the lower bound of the fogging time range as well as the

154 insecticide used were chosen to simulate effects of conventional fogging practices for

155 mosquitoes. KDCF itself is not normally fogged directly, but the study sites we chose were likely

156 to experience spillover effects from nearby fogging and are thus ideal to investigate the indirect

157 effects of fogging (Fig. 1). Nevertheless, mosquito populations remain relatively high in the

$158 \mathrm{KDCF}$, as hikers often spray insecticide on their exposed body parts to ward off mosquito bites

159 (Wong EL, 2019, pers. comm.).

160

161 Figure 2. Fogging experiments set-up and example of invertebrate collected.

162 (A) Licensed foggers using hand-held pulse thermal fog generators to fog one of the study site.

163 (B) The fogging chemical Detral 2.5 EC brand used for in this study. The active chemical

164 (deltamethrin $2.5 \% \mathrm{w} / \mathrm{w}$ ) is a form of synthetic Pyrethroid, claimed to be an effective insecticide

165 targeting houseflies and mosquitoes. (C) Two $2.5 \mathrm{~m}$ and two $1.25 \mathrm{~m}$ polyethylene sheets set-up

166 under the tree to fully cover the canopy of the site to maximize capture of knockdown

167 invertebrate from the site. The sheets are held off the forest floor using $70 \mathrm{~cm}$ stakes to prevent

168 leaf-litter invertebrates from crawling onto the sheets. (D) An example of dead invertebrate

169 (order Araneae) due to fogging insecticide.

170

171 To collect knocked down invertebrates, two $2.5 \mathrm{~m}$ and two $1.25 \mathrm{~m}$ white polyethylene sheets

172 were set up under the tree corresponding approximately to the canopy cover (Fig. 2c). The sheets

173 were held up off the forest floor by $70 \mathrm{~cm}$ stakes to prevent the leaf-litter invertebrates from

174 crawling onto the polyethylene sheets. Invertebrates knocked down by the fog onto the sheets

175 were carefully collected five minutes post fogging treatment into plastic containers that were

176 covered with small nets for ventilation. Collected invertebrates were brought back to the lab for

177 classification and sorting.

178 
179 Impact of fogging on target and non-target invertebrate taxa

180 To assess whether fogging was effective in killing its target invertebrate taxon (Diptera), and the 181 extent to which it was detrimental to non-target invertebrate orders, we recorded their mortality

182 3-hr after the fogging treatment. This time frame was chosen to understand the short-term effects 183 of fogging on non-target invertebrate mortality rates. Invertebrates that responded to a light touch 184 stimulus were categorised as 'alive' and those that remained motionless as 'dead'. Each

185 invertebrate was then sorted into their respective orders based on their morphological

186 characteristics with appropriate taxonomic keys (McGavin, 1990; Imes, 1992).

187

\section{Impact of fogging on foraging behaviour of an invertebrate pollinator}

189 To determine whether fogging was detrimental on the foraging behaviour of invertebrate

190 pollinators, we selected Lepidoptera as the focal taxon as they are important tropical pollinators,

191 easily recognizable and also play a vital role as environmental indicators (Tzortzakaki et al.,

192 2019). We counted the number of live butterflies occurring at each of the 10 sites pre- and post-

193 fogging. On each day of the fogging treatment, the number of butterflies recorded in the $500 \mathrm{~m}$

194 radius of the site was recorded by two observers, each responsible for half of the radius. The

195 counting of live butterflies was conducted for $30 \mathrm{~min}$ pre-fogging treatment. For post-fogging

196 count, the same observation radius was repeated with the same observers, at the same site and

197 time (approximately $1000 \mathrm{~h}$ ) for the same duration of time (30 $\mathrm{min}) 24$ hours after fogging

198 treatment.

199

200

\section{Statistical analysis}

201 We analysed the data collected from 10 sample sites in a Bayesian framework to quantify the 202 impact of fogging on counts of live individuals of: 1) Diptera 3-hr post-fogging; 2) selected 203 invertebrate taxa 3-hr post-fogging (taxa selected based on detections in at least 8 of 10 sites); 204 and 3) an invertebrate pollinator (Lepidoptera) 24-hr post-fogging. We constructed Bayesian 205 hierarchical Poisson regression models that are more suited for overdispersed count data. All 206 analysis was conducted in R ver. 3.5.3 using package 'jagsUI' and 'mcmcOutput'.

207

208

209 


\section{Results}

211 A total of 1874 invertebrates were collected from 19 different orders after the 3-hr post fogging

212 treatments. An 'Unknown' order consisting of 13 individuals could not be identified based on its

213 morphological characteristics. These individuals are mostly immature forms of the invertebrates

214 (Table 1). Of the total number of invertebrates collected, 72.7\% (1363) were knocked down by

215 fogging and considered 'dead', where Hymenoptera (18.0\% of total knockdown insects) was the

216 most abundant (majority were ants) and Diptera (8.8\% of total knockdown insects) being the

217 third most abundant order recorded as 'dead' (Table 1). Out of all the Diptera individuals

218 knocked down, no mosquitoes were collected, despite their presence verified by field researchers

219 who were bitten by them during fogging experiments.

220

221

Table 1: Summary statistics of knocked-down invertebrate taxa after the 3-hr post fogging

222 treatment across 10 sites in Kota Damansara Community Forest (KDCF), Selangor,

223 Peninsular Malaysia.

224 The table is ordered from the most abundant to the least abundant knocked down invertebrate 225 orders.

226

\section{Impact of fogging on target invertebrate taxon and non-target invertebrate taxa}

Our regression models showed that given the data and prior information, the probability that

to $11 \%$ of the original pre-fogging count of live individuals for the target invertebrate taxon (Fig. 3 ), and reductions to between $5 \%$ to $58 \%$ of the original pre-fogging count of live individuals for non-target invertebrate taxa (Supplementary Figure 1).

Figure 3. Graphs displaying the impact of fogging on the target invertebrate taxon (Diptera) across 10 sample sites. 
239 post-fogging was $100 \%$, with reductions to $11 \%$ of the pre-fogging count of live individual, with 240 the 95\% Highest Density Interval (HDI) ranging between 5.8\% and 16.1\%. (B) A violin plot

241 representing the distribution of "Dead" and "Alive" Diptera individuals found across the 10

242 sample sites. The distributions indicate that there are less "Alive" Diptera 3-hrs post-fogging.

243 This can be seen in the larger distribution observed at the lower values of the "Alive" violin plot.

244

\section{Impact of fogging on an invertebrate pollinator}

246 Our regression models showed that given the data and prior information, the probability that

247 fogging had a negative effect 24-hr post-fogging was also $100 \%$, with reductions to $53 \%$ of the

248 original pre-fogging count of live individuals (Fig. 4).

249

250

Figure 4. Graphs displaying the impact of fogging on the invertebrate pollinator (Lepidoptera) across 10 sample sites.

252

(A) Plot of marginal posterior probability distributions for our Bayesian hierarchical Poisson

253 regression model, showing the probability that fogging had a negative effect on Lepidoptera 24$\mathrm{hr}$ post-fogging was $100 \%$, with reductions to $53 \%$ of the pre-fogging count of live individuals, with the 95\% Highest Density Interval (HDI) ranging between 36.5\% and 70\%. (B) A violin plot representing the distribution Lepidoptera observations "Before" and "After" fogging across the 10 sample sites. The distributions indicate that there are less Lepidoptera observations $24-\mathrm{hr}$ post-fogging treatment. This is observed where the distribution of data is larger at the lower values of the "After" violin plot.

\section{Discussion}

262 To our knowledge, this is the first study to demonstrate short-term detrimental effects of mosquito fogging on urban invertebrates in a tropical city in Southeast Asia. Our results demonstrate that the fogging insecticide had an unintended adverse effect on non-target invertebrates, which is characterized in this study as negative effects on invertebrates that were not mosquitoes. Similar results were also observed by Abeyasuriya et al. (2017) in Sri Lanka, where more dead than alive individuals were recorded amongst the 12 insect orders sampled post- 24-hr fogging. 
Our findings are, however, not concordant with previous studies that found that Diptera

270

271

272

273

274

275

276

277

278

279

280

281

282

283

284

285

286

287

288

289

290

291

292

293

294

295

296

297

298 was among the most affected by fogging (Kwan et al., 2009; Abeyasuriya et al., 2017). In our results, Hymenoptera (consisting of ants, wasps and bees)) was the most affected by fogging (Table 1). One possible explanation could be sites from both Abeyasuriya et al. (2017) and Kwan et al. (2009) studies had very different target and non-target invertebrate compositions, which are very dependent on the floral composition and the niches available at each site (Toft et al., 2019). At our study sites, the floral composition is of natural secondary forest composition, whereas Abeyasuriya et al. (2017) and Kwan et al. (2009) studies focussed on cultivated landscapes. Our results (Figure 3) show that while the effectiveness of the insecticide in rendering more Diptera individuals "Dead" post-fogging is high, the selectivity of the insecticide towards mosquito species is low as none of the individuals were mosquitoes.

The unintended effect of fogging on non-target invertebrates is alarming as many of them play vital functions in urban ecosystems. Thysanoptera, for example, encompassing $11 \%$ of the total knocked down samples, was the sixth most affected order with 76.4\% 'dead' 3-hr postfogging. Commonly known as thrips, these invertebrates are important pollinators for many Dipterocarpaceae, an important hard-wood tree family that make up Southeast Asia's rainforest tree communities (Apanah \& Chan, 1981). Thrips are also pollinators of Macaranga species (Fiala et al., 2011), an important pioneer tree genus for forest regeneration in Malaysia (Daisuke et al., 2013). An adverse effect on thrips diversity and numbers could severely disrupt pollination cycles of these two very important tree families, affecting existing dipterocarp tree biodiversity and might impede any forest restoration projects that plants Macaranga species.

Our study also reflects the varying degrees of insecticide susceptibility in invertebrates. Insecticide penetration may be less efficient in invertebrates with thicker cuticles and thus decrease their susceptibility to insecticides (Dang et al., 2017). Our results show that fogging appears to have more detrimental impacts on invertebrates with comparatively lower levels of chitinisation (e.g. live individuals of Psocoptera were reduced to $5 \%$ of pre-fogging count; Supplementary Figure 1). As recorded in other studies (e.g. Boyce et al., 2007), invertebrates with relatively 'softer' bodies may permit easier entry of pyrethroids such as deltamehrin through contact as one of the primary modes of action (Chrustek et al., 2018). In contrast, Coleoptera, which have relatively higher levels of chitinisation due to unique adaptations of 
299 hardened forewings and compact bodies McGavin, 1990; Imes, 1992), appeared to be more

300 resistant to fogging (reduced to only $58 \%$ of pre-fogging count of live individuals;

301 Supplementary Figure 1). Our results are consistent with a study by Abeyasuriya et al. (2017)

302 where insects belonging to the order Coleoptera had the lowest mortality rate in two out of their

303 three study sites. Even though hardened adult Coleoptera are more resistant to fogging

304 insecticides, its larvae stages could still be affected.

305 Our findings indicate that fogging also has negative impacts on invertebrate pollinators

306 such as butterflies. Sublethal exposure to insecticide can lead to changes in Lepidoptera foraging

307 behavior and oviposition as the insecticides may alter the odor emitted by the plant (de Franca et

308 al., 2017). This could be due to pollinators avoiding the insecticides that may be present in pollen

309 and nectar (van der Sluijs et al., 2013) or the fog has not dispersed completely under the dense

310 canopy. Furthermore, studies indicate that insecticides which target the nervous systems of

311 invertebrates reduce pollinator survival and reproduction rates (Abeyasuriya et al., 2017; de

312 Franca et al., 2017). While immediate fogging may not directly affect pollinators such as

313 butterflies and bees, these organisms may become exposed to these chemicals through feeding

314 and foraging (Braak et al., 2018) as pyrethroids have been shown to stick to pollen (Pettis et al.,

315 2013). As evidenced from our study, most Lepidoptera individuals that were affected by fogging

316 were caterpillars feeding on the vegetation when the fog hit. Future studies can focus on counting

317 the number of Lepidoptera individuals in the fogged area for a longer period to investigate the

318 extent they can recover to pre-fogging conditions. This result could give an indication of the

319 length the fog persists on the surrounding vegetation. As our study only examined short-term

320 effects of fogging on Lepidoptera, it is still unclear whether fogging has any long-term effects on

321 pollinator behavior or physiology.

322

In general, there is still a paucity of information on threats to invertebrate communities in

323 urban areas. Most urban ecology studies have focused on the consequences of pollinator species

324 decline (Thogmartin et al., 2017; Meeus et al., 2018; Wepprich et al., 2019), but very few studies

325 have examined the consequences of general invertebrate decline. One possible consequence of

326 the decline in non-target invertebrates is a negative effect on the survival of insectivorous birds,

327 frogs, lizards and other invertebrate predators (spiders, wasps etc) that rely on invertebrates in

328 their diet (Sanchez-Bayo \& Wyckhuys, 2019). While fogging may not kill all invertebrates, the 
329 sub-lethal dosage exposed to these invertebrates may also have possible consequences on their

330 biology, physiology and behavior (de Franca et al., 2017). Fogging may also lead to the

331 homogenization of invertebrate species with generalist dominating the remnant habitat, reducing

332 diversity and disrupting invaluable ecosystem services such as pollination, decomposition and

333 nutrient cycling (Sanchez-Bayo \& Wyckhuys, 2019).

335 Caveats

336 Our results could have been more robust if we had adopted a Before-After-Control-Impact

337 (BACI) design, but limited resources were a constraint. We also acknowledge that our results

338 were only reflective for the number of knocked-down insects that had dropped onto the

339 collection sheets - they do not take into account the number of invertebrates, unaffected or

340 affected, which remained in the canopy post-fogging. Future studies could account for this bias

341 by sampling the canopy level and hidden crevices and leaves for a better representation of

342 unaffected and affected invertebrates. Furthermore, as this study examines the short-term effects

343 of fogging on non-target invertebrates, the cut-off timing for 'Dead' or 'Alive' categorization

344 should be extended in future studies. This is to ensure that long-term effects can be captured by

345 recording the number of invertebrates, initially recorded as 'Alive' that eventually succumbed.

346 Abeyasuriya et al. (2017) used a $24 \mathrm{hr}$ window as their cut-off point, and future study could

347 benefit by mirroring this $24-\mathrm{hr}$ period. While our study has documented invertebrates that are

348 adversely affected by fogging, it would have been ideal to identify invertebrates to

349 morphospecies to accurately determine differences in species diversity and richness affected by

350 fogging. However, many of the invertebrates collected were relatively small and of immature

351 developmental stages where identification keys were absent. Metabarcoding could be explored in

352 the future to obtain more accurate representation of species diversity. By doing so, the ecological

353 functional groups of the invertebrates affected by fogging can also be identified.

\section{Conclusion}


356 Overall, our study shows that insecticide fogging is detrimental to non-target invertebrates,

357 particularly pollinators and species that have comparatively lower levels of chitinisation.

358 Alternative methods of mosquito control should be explored in order to reduce health risks in

359 tropical cities, while preserving other forms of urban biodiversity.

360

\section{Acknowledgements}

362 We thank Ms. Harlina Binti Md Yunus and Forestry Department Malaysia for permission and

363 logistics assistance. The fogging experiment could not run smoothly without the help from Ms

364 Deniece Yeo Yin Chia, Ms Taneswarry Sethu Pathy and Mr Jason Yew Seng Gan that assist in

365 fogging experiments and subsequent invertebrate sorting. We also thank Ms Wong Ee Lyn and

366 Kota Damansara Community Forest (KDCF) regular hikers for inviting us to conduct this

367 experiment at their managed forest to understand the effect of fogging on urban biodiversity.

368 Finally, we are grateful to Mike Meredith for his advice on the statistical analyses.

369

370

\section{References}

371

Abeyasuriya KGTN, Nugapola NWNP, Perera MDB, Karunaratne WAIP, Karunaratne

372

SHPP. 2017. Effect of dengue mosquito control insecticide thermal fogging on non-target

373 insects. International Journal of Tropical Insect Science 37(1):11-18. DOI:

374 $10.1017 / \mathrm{S} 1742758416000254$

375

Amal AR, Malina O, Rukman AH, Zasmy UN, Omar AW, Norhafizah M. 2011. The impact

376 of preventive fogging on entomological parameters in a university campus in Malaysia.

377 Malaysian Journal of Medicine and Health Sciences 7(1):9-15.

378 Amin L, Arham AF, Mahadi Z, Razman MR, Rusly NS. 2019. Stakeholder's attitude towards fogging technique in Malaysia. Akademika 89(2):187-200. DOI: https://doi.org/10.17576/akad380 $\underline{2019-8902-14}$

381 Apanah S, Chan HT. 1981. Thrips: the pollinators of some dipterocarps. Malaysian Forester $382 \quad 44(2-3): 234-252$. 
383 Benelli G, Jeffries CL, Walker T. 2016. Biological control of mosquito vectors: Past, present, 384 and future. Insects 7(4):52. DOI: 10.3390/insects7040052

385 Boyce WM, Lawler SP, Schultz JM, McCauley SJ, Kimsey LS, Niemela MK, Nielsen CF, 386 Reisen WK. 2007. Nontarget effects of the mosquito adulticide pyrethrin applied aerially during 387 a West Nile virus outbreak in an urban California environment. Journal of the American 388 Mosquito Control Association 23(3):335-9. DOI: 10.2987/8756-

389 971X(2007)23[335:NEOTMA]2.0.CO;2

390 Braak N, Neve R, Jones AK, Gibbs M, Brueker J. 2018. The effects of insecticides on

391 butterflies - A review. Environmental Pollution 242:507-518. DOI:

392 https://doi.org/10.1016/j.envpol.2018.06.100

393 Chrustek A, Hołyńska-Iwan I, Dziembowska I, Bogusiewicz J, Wróblewski M, Cwynar A, 394 Olszewska-Słonina D. 2018. Current research on the safety of pyrethroids used as insecticides. 395 Medicina (Kaunas) 54(4):61. DOI: 10.3390/medicina54040061

396 Clark PJ, Reed JM, Chew FS. 2007. Effects of urbanization on butterfly species richness, guild 397 structure, and rarity. Urban Ecosystem 10:321-337. DOI: 10.1007/s11252-007-0029-4

398 Daisuke H, Tanaka K, Jawa KJ, Ikuo N, Katsutoshi S. 2013. Rehabilitation of degraded 399 tropical rainforest using dipterocarp trees in Sarawak, Malaysia. International Journal of 400 Forestry Research 2013(2013):1-11.

401 Dang K, Doggett, SL, Singham GV, Lee, C-Y. 2017. Insecticide resistance and resistance 402 mechanisms in bed bugs, Cimex spp. (Hemiptera: Cimicidae). Parasites and Vectors 10(318). 403 DOI 10.1186/s13071-017-2232-3

404 de França SM, Breda MO, Barbosa DRS, Araujo AMN, Guedes CA. 2017. The sublethal 405 effects of insecticides in insects. In: Shields VDC, ed.. Biological Control of Pest and Vector 406 Insects. London: IntechOpen 23-39.

407 Demok S, Endersby-Harshman N, Vinit R, Timinao L, Robinson LJ, Susapu M, Makita L, 408 Laman M, Hoffman A, Karl, K. 2019. Insecticide resistance status of Aedes aegypti and Aedes 
409 albopictus mosquitoes in Papua New Guinea. Parasites and Vectors 12(1):333. DOI:

410 https://doi.org/10.1186/s13071-019-3585-6

411 Eisenhauer N, Bonn A, Guerra CA. 2019. Recognizing the quiet extinction of invertebrates.

412 Nature Communications 10(1):50. DOI: https://doi.org/10.1038/s41467-018-07916-1

413 European Centre for Disease Prevention and Control. 2019, 19 October. Communicable

414 disease threats report. Retrieved from https://www.ecdc.europa.eu/en/publications-

415 data/communicable-disease-threats-report-13-19-october-2019-week-42

416 Fiala B, Ute M,_Hasim R, Maschwitz U. 2011. Pollination systems in pioneer trees of the genus 417 Macaranga (Euphorbiaceae) in Malaysian rainforests. Biological Journal of the Linnean Society 418 103(4):935-953. DOI: 10.1111/j.1095-8312.2011.01680.x

419 Ferreira R, Martins P, Dutra C, Mentone M, Antonini, B. 2013. Old fragments of forest 420 inside an urban area are able to keep orchid bee (Hymenoptera: Apidae: Euglossini)

421 assemblages? The case of a Brazilian historical city. Neotropical Entomology 42(5): 466-473.

422 DOI: https://doi.org/10.1007/s13744-013-0145-1

423 Forman RT. 2014. Urban ecology: science of cities. Cambridge University Press.

424 Fournet F, Jourdain F, Bonnet E, Degroote S, Ridde V. 2018. Effective surveillance systems 425 for vector-borne diseases in urban settings and translation of the data into action: a scoping 426 review. Infectious Diseases of Poverty 7(1):99. DOI: https://doi.org/10.1186/s40249-018-0473-9

427 Hennig EI, Ghazoul J. 2011. Pollinating animals in the urban environment. Urban Ecosystems 428 15(1):149-166. DOI: 10.1007/s11252-011-0202-7

429 Hülsmann M, von Wehrden H, Klein A-M, Leonhardt SD. 2015. Plant diversity and 430 composition compensate for negative effects of urbanization on foraging bumble bees.

431 Apidologie 46:760-770. DOI: https://doi.org/10.1007/s13592-015-0366-X

432 Imes R. 1992. The practical entomologist. New York, N.Y: Simon and Schuster.

433 Khadijah AR, Azizah AA, Meor SR. 2013. Diversity and abundance of insect species at Kota 434 Damansara Community Forest Reserve, Selangor. Scientific Research and Essays 8(9):359-374. 435 DOI 10.5897/SRE12.481 
436 Kim S, Chen Z, Zhang Z, Simons-Morton BG, Albert PS. 2013. Bayesian hierarchical 437 Poisson regression models: an application to a driving study with kinematic events. Journal of 438 the American Statistical Association 108: 494-503.

439 Knudsen AB, Slooff R. 1992. Vector-borne disease problems in rapid urbanization: new 440 approaches to vector control. Bulletin of the World Health Organization 70(1):1-6.

441 Koou S-Y, Chong C-S, Vythilingam I, Ng L-C, Lee C-Y. 2014. Pyrethroid resistance in Aedes 442 aegypti larvae (Diptera: Culicidae) from Singapore. Journal of Medical Entomology 51(1):170443 181. DOI: https://doi.org/10.1603/ME13113

444 Kwan JA, Novak MG, Hyles TS, Niemela MK. 2009. Mortality of nontarget arthropods from 445 an aerial application of pyrethrins. Journal of the American Mosquito Control Association 446 25(2):218-20. DOI: 10.2987/08-5858.1

447 Lee JM, Wasserman RJ, Gan JY, Wilson RF, Rahman S, Yek, SH. 2019. Human activities 448 attract harmful mosquitoes in a tropical urban landscape. EcoHealth 17(1):52-63. DOI 449 10.1007/s10393-019-01457-9

450 MacGregor CJ, Pocock MJO, Fox R, Evans DM. 2015. Pollination by nocturnal Lepidoptera, 451 and the effects of light pollution: a review. Ecological Entomology 40(3):187-198. DOI: $45210.1111 /$ een.12174

453 Marcombe S, Darriet F, Tolosa M, Agnew P, Duchon S, Etienne M, Yp Tcha MM, 454 Chandre F, Corbel V, Yébakima A. 2011. Pyrethroid resistance reduces the efficacy of space 455 sprays for dengue control on the island of Martinique (Caribbean). PLoS Neglected Tropical 456 Diseases 5(6):e1202. DOI: 10.1371/journal.pntd.0001202

457 McGavin GC. 1990. Insects, spiders and other terrestrial arthropods. New York, NY: Dorling 458 Kinderseley Inc.

459 Meeus I, Pisman M, Smagghe G, Piot N. 2018. Interaction effects of different drivers of wild 460 bee decline and their influence on host-pathogen dynamics. Current Opinion in Insect Science 461 26:136-141 
462 Pettis JS, Lichtenberg EM, Andree M, Stitzinger J, Rose R, Vanengelsdorp D. 2013. Crop

463 pollination exposes honey bees to pesticides which alters their susceptibility to the gut pathogen

464 Nosema ceranae. PLoS ONE 8(7):e70182.

465 Rollings R, Goulson D. 2019. Quantifying the attractiveness of garden flowers for

466 pollinators. Journal of Insect Conservation 23(5-6):803-817.

467 Sánchez-Bayo F, Wyckhuys KAG. 2019. Worldwide decline of the entomofauna: A review of 468 its drivers. Biological Conservation, 232:8-27. DOI:

469 https://doi.org/10.1016/j.biocon.2019.01.020

470 Shafie FA, Tahir MPM, Sabri NM. 2012. Aedes mosquitoes resistance in urban community 471 setting. Procedia - Social and Behavioral Sciences 36:70-76. DOI:

472 10.1016/j.sbspro.2012.03.008

473 Thogmartin WE, Wiederholt R, Oberhauser K, Drum RG, Diffendorfer JE, Altizer S, 474 Taylor OR, Pleasants J, Semmens D, Semmens B, Erickson R, Kaitlin L, Lopez-Hoffman

475 L. 2017. Monarch butterfly population decline in North America: identifying the threatening 476 processes. Royal Society Open Science 4(9): 170760.

477 Toft RJ, Ford DE, Sullivan JJ, Stewart GH. 2019. Invertebrates of an urban old growth forest 478 are different from forest restoration and garden communities. New Zealand Journal of 479 Ecology 43(1):1-10.

480 Tzortzakaki O, Kati V, Panitsa M, Tzanatos E, Giokas S. 2019. Butterfly diversity along the 481 urbanization gradient in a densely-built Mediterranean city: Land cover is more decisive than 482 resources in structuring communities. Landscape and Urban Planning 183: 79-87. DOI:

483 https://doi.org/10.1016/j.landurbplan.2018.11.007

484 Usuga AF, Zuluaga-Idárraga LM, Alvarez N, Roho R, Henao E, Rúa-Uribe GL. 2019.

485 Barriers that limit the implementation of thermal fogging for the control of dengue in Colombia:

486 a study of mixed methods. BioMed Central Public Health 19(1): 1-10. DOI:

487 https://doi.org/10.1186/s12889-019-7029-1 
488 van der Sluijs JP, Simon-Delso N, Goulson D, Maxim L, Bonmatin J-M, Belzunces LP.

489 2013. Neonicotinoids, bee disorders and the sustainability of pollinator services. Current

490 Opinion in Environmental Sustainability 5(3-4): 293-305.

491 Wepprich T, Adrion JR, Ries L, Wiedmann J, Haddad NM. 2019. Butterfly abundance

492 declines over 20 years of systematic monitoring in Ohio, USA. PLoS ONE 14(7): e216270.

493 World Health Organization (WHO). 2017. Vector-borne disease. Available at

494 https://www.who.int/news-room/fact-sheets/detail/vector-borne-diseases (accessed 8 October 495 2019).

496 Yaakob U, Masron T, Masami F. 2012. Ninety years of urbanization in Malaysia: A

497 geographical investigation of its trends and characteristics. Ritsumeikan Journal of Social

498 Sciences and Humanities 79-102.

499 Zhang XQ. 2016. The trends, promises and challenges of urbanisation in the world. Habitat

500 International 54(3): 241-252. DOI: https://doi.org/10.1016/j.habitatint.2015.11.018

501

502

503

504

505

506

507

508

509

510

511

Peer] reviewing PDF | (2020:02:46264:2:0:NEW 21 Aug 2020) 


\section{SUPPLEMENTARY INFORMATION}

513 Supplementary Table 1 . GPS Coordinates of 10 sites at KDCF

514

515 Supplementary Figure 1. Plots of marginal posterior probability distributions for our Bayesian

516 hierarchical Poisson regression model, showing the probability that fogging had a negative effect

517 on 10 non-target invertebrate taxa 3 -hr post-fogging was $100 \%$, with reductions of $5 \%$ to $58 \%$ of

518 the pre-fogging count of live individuals, with the $95 \%$ Highest Density Interval (HDI) shown

519 for each taxon.

520

521 Supplementary Dataset 1 . The raw data of dead and alive invertebrates at 10 sites from fogging 522 experiments

523

524 Supplementary Dataset 2. The raw data from butterfly observation 1-hr pre-fogging and $24 \mathrm{hr}$ 525 post fogging

526

527 Supplementary Dataset 3. Sample R code for Bayesian hierarchical Poisson regression models 528 for the butterfly (Lepidoptera) dataset. 
Figure 1

The study site - Kota Damansara Community Forest Reserve (KDCF)

The entrance to KDCF (filled circle) is surrounded by a government school - SMK Seksyen 10 Kota Damansara (dark grey square), the high rise condominium - De Rozelle (dark grey triangle). KDCF experiences regular fogging by different private companies in an effort to control vector-borne mosquito diseases (Kota Damansara residents, 2019, pers. comm.). Image credit: OpenClipart at https://freesvg.org/.

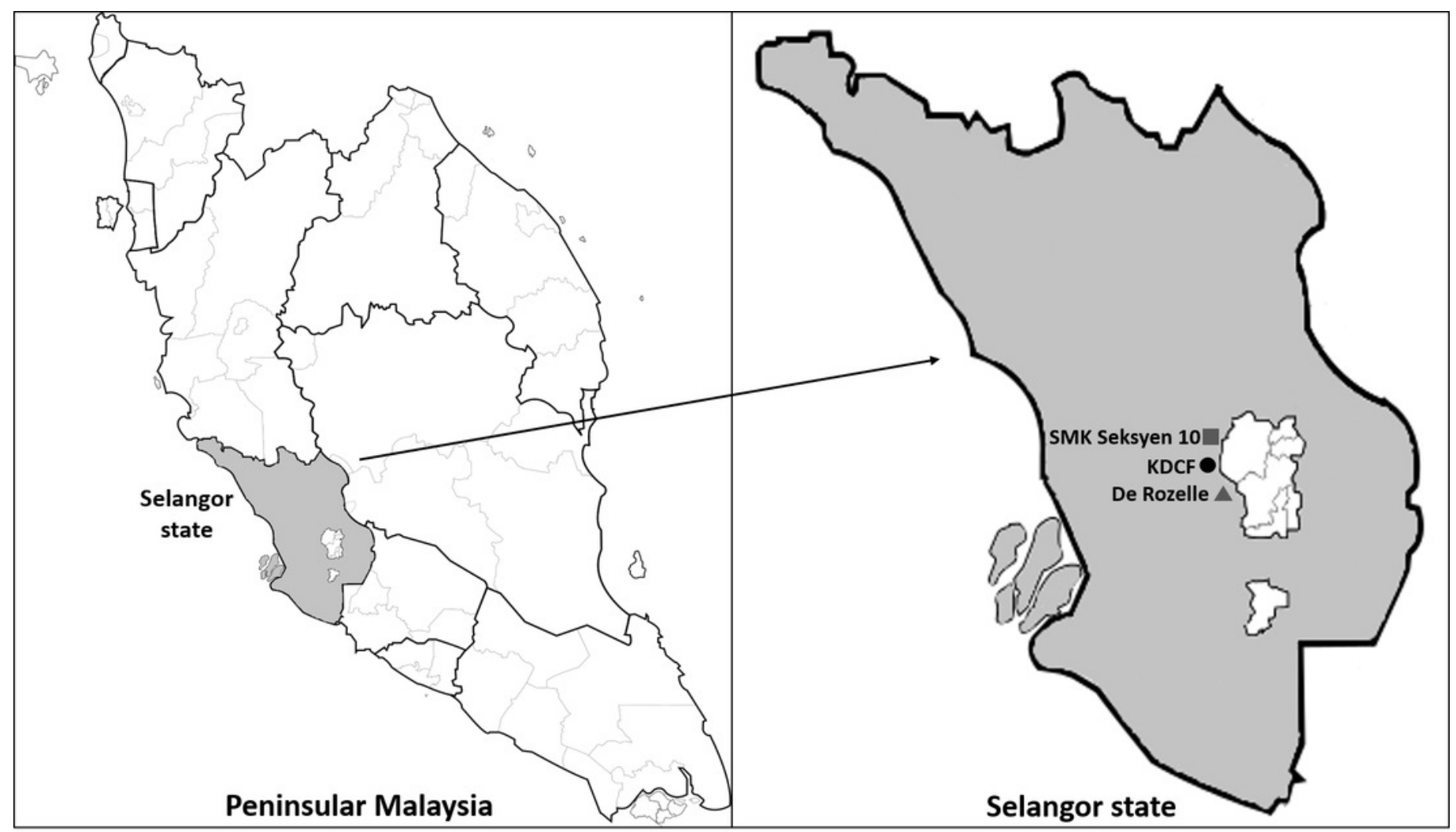




\section{Figure 2}

Fogging experiments set-up and example of invertebrate collected.

(A) Licensed foggers using hand-held pulse thermal fog generators to fog one of the study site. (B) The fogging chemical Detral 2.5 EC brand used for in this study. The active chemical (deltamethrin $2.5 \% \mathrm{w} / \mathrm{w}$ ) is a form of synthetic Pyrethroid, claimed to be an effective insecticide targeting houseflies and mosquitoes. (C) Two $2.5 \mathrm{~m}$ and two $1.25 \mathrm{~m}$ polyethylene sheets set-up under the tree to fully cover the canopy of the site to maximize capture of knockdown invertebrate from the site. The sheets are held off the forest floor using $70 \mathrm{~cm}$ stakes to prevent leaf-litter invertebrates from crawling onto the sheets. (D) An example of dead invertebrate (order Araneae) due to fogging insecticide. 


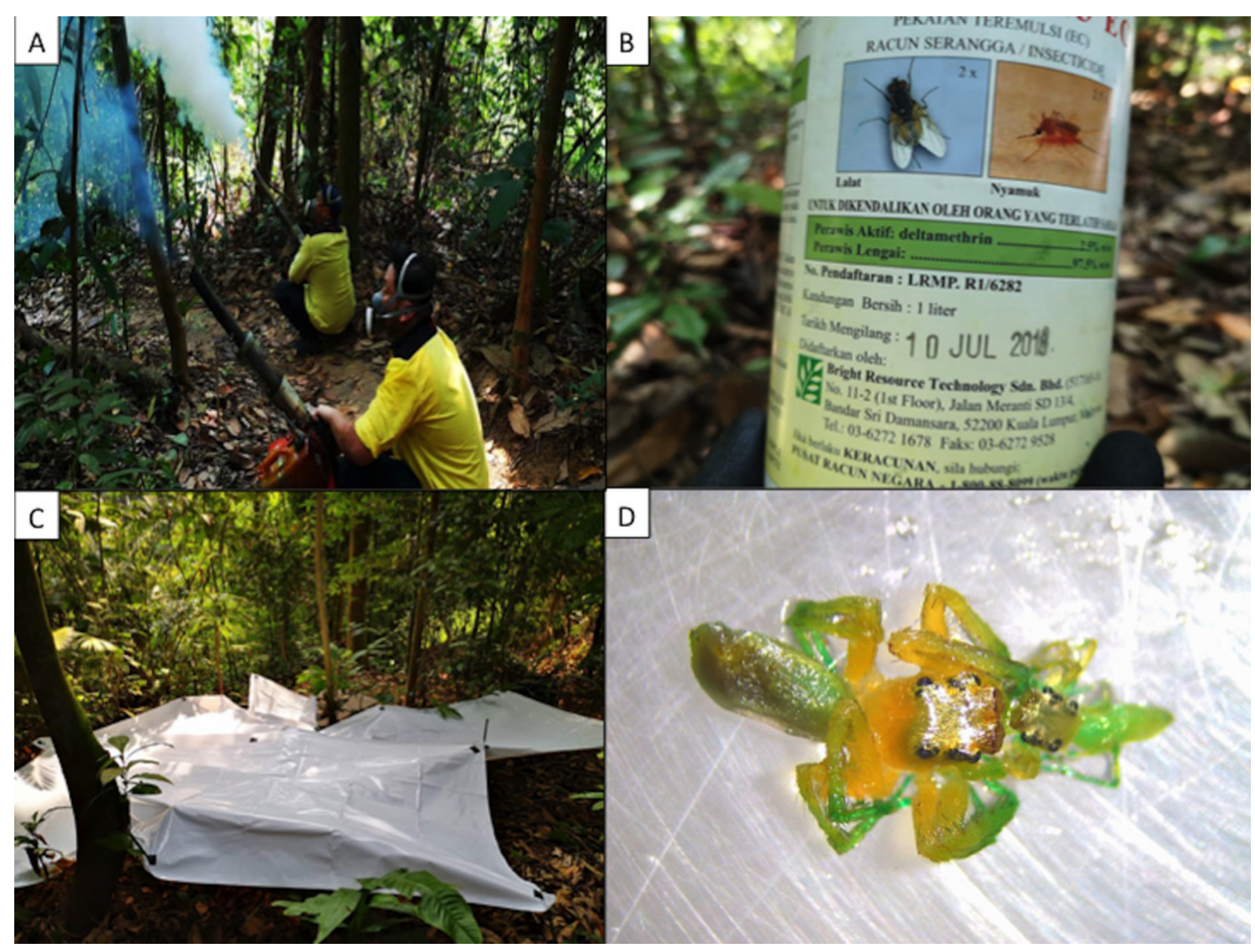




\section{Table $\mathbf{1}$ (on next page)}

Summary statistics of knocked-down invertebrate taxa after the 3-hr post fogging treatment across 10 sites in Kota Damansara Community Forest (KDCF), Selangor, Peninsular Malaysia. .

The table is ordered from the most abundant to the least abundant knocked down invertebrate orders. 


\begin{tabular}{|c|c|c|c|c|}
\hline Order & $\begin{array}{c}\text { Number of } \\
\text { knocked down } \\
\text { invertebrates }\end{array}$ & Dead & Alive & $\begin{array}{c}\text { Mortality 3 hr } \\
\text { post-fogging } \\
\text { (\%) }\end{array}$ \\
\hline Hymenoptera & 337 & 217 & 120 & 64.4 \\
\hline Araneae & 296 & 238 & 58 & 80.5 \\
\hline Hemiptera & 209 & 144 & 65 & 68.9 \\
\hline Thysanoptera & 208 & 159 & 49 & 76.4 \\
\hline Coleoptera & 185 & 79 & 106 & 42.7 \\
\hline Diptera & 166 & 148 & 18 & 89.2 \\
\hline Collembola & 118 & 115 & 3 & 97.5 \\
\hline Psocoptera & 112 & 106 & 6 & 94.6 \\
\hline Acari & 63 & 47 & 16 & 74.6 \\
\hline Blattodea & 51 & 38 & 13 & 74.5 \\
\hline Orthoptera & 57 & 33 & 24 & 57.9 \\
\hline Lepidoptera & 29 & 17 & 12 & 58.6 \\
\hline Pseudoscorpiones & 10 & 2 & 8 & 20.0 \\
\hline Archaeognatha & 5 & 4 & 1 & 80.0 \\
\hline Neuroptera & 5 & 3 & 2 & 60.0 \\
\hline Opiliones & 4 & 3 & 1 & 75.0 \\
\hline Phasmotodea & 3 & 0 & 3 & 0.0 \\
\hline Diplopoda & 2 & 1 & 1 & 50.0 \\
\hline Mantodea & 1 & 0 & 1 & 0.0 \\
\hline Unknown & 13 & 9 & 4 & 69.2 \\
\hline Total & 1874 & 1363 & 511 & 72.7 \\
\hline
\end{tabular}




\section{Figure 3}

Graphs displaying the impact of fogging on the target invertebrate taxon (Diptera) across 10 sample sites.

(A) Plot of marginal posterior probability distributions for our Bayesian hierarchical Poisson regression model, showing the probability that fogging had a negative effect on Diptera 3-hr post-fogging was $100 \%$, with reductions to $11 \%$ of the pre-fogging count of live individual, with the 95\% Highest Density Interval (HDI) ranging between $5.8 \%$ and $16.1 \%$. (B) A violin plot representing the distribution of "Dead" and "Alive" Diptera individuals found across the 10 sample sites. The distributions indicate that there are less "Alive" Diptera 3-hrs postfogging. This can be seen in the larger distribution observed at the lower values of the "Alive" violin plot.

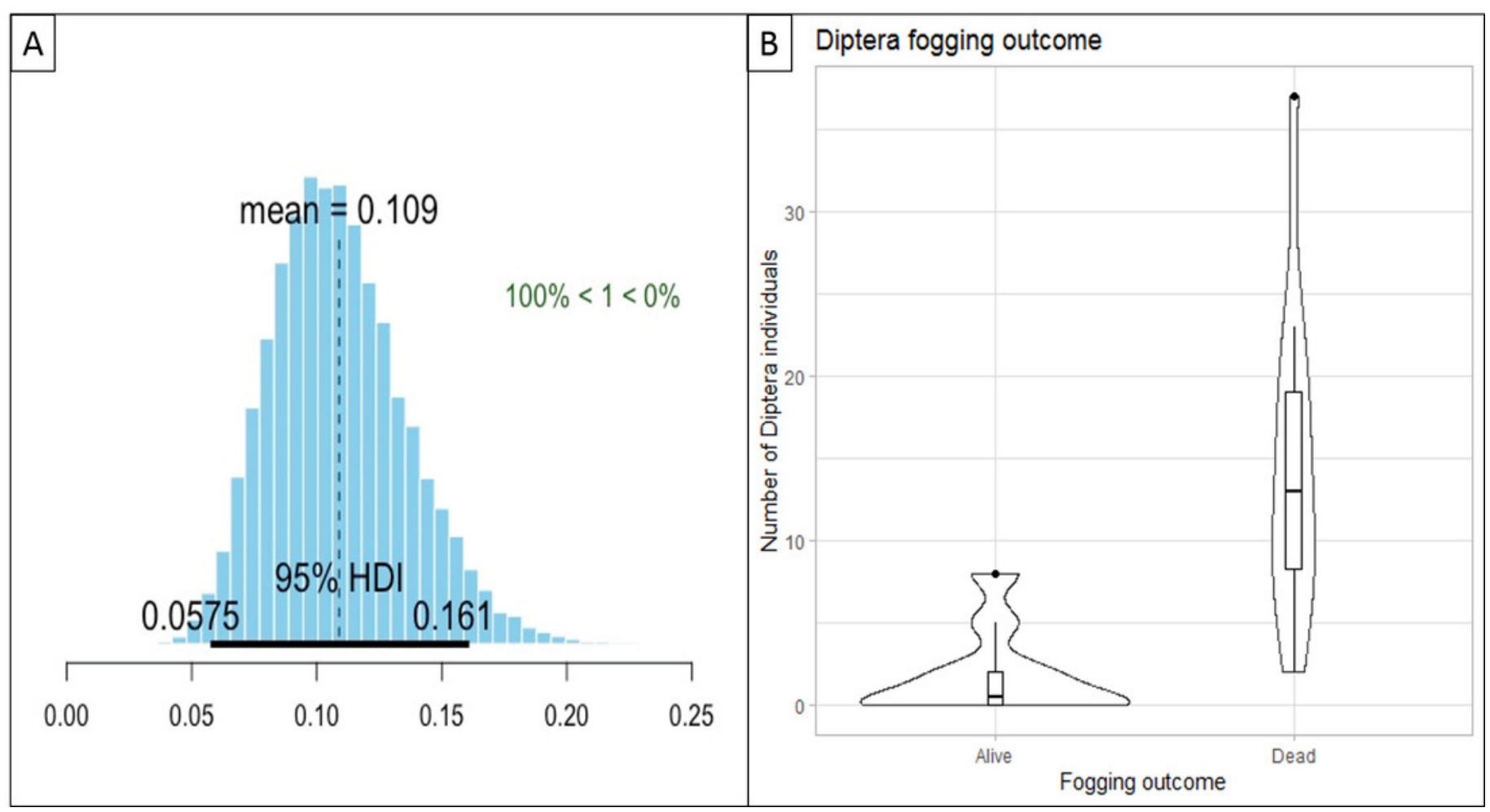




\section{Figure 4}

Graphs displaying the impact of fogging on the invertebrate pollinator (Lepidoptera) across 10 sample sites.

(A) Plot of marginal posterior probability distributions for our Bayesian hierarchical Poisson regression model, showing the probability that fogging had a negative effect on Lepidoptera 24 -hr post-fogging was $100 \%$, with reductions to $53 \%$ of the pre-fogging count of live individuals, with the 95\% Highest Density Interval (HDI) ranging between $36.5 \%$ and $70 \%$. ( B) A violin plot representing the distribution Lepidoptera observations "Before" and "After" fogging across the 10 sample sites. The distributions indicate that there are less Lepidoptera observations 24-hr post-fogging treatment. This is observed where the distribution of data is larger at the lower values of the "After" violin plot.

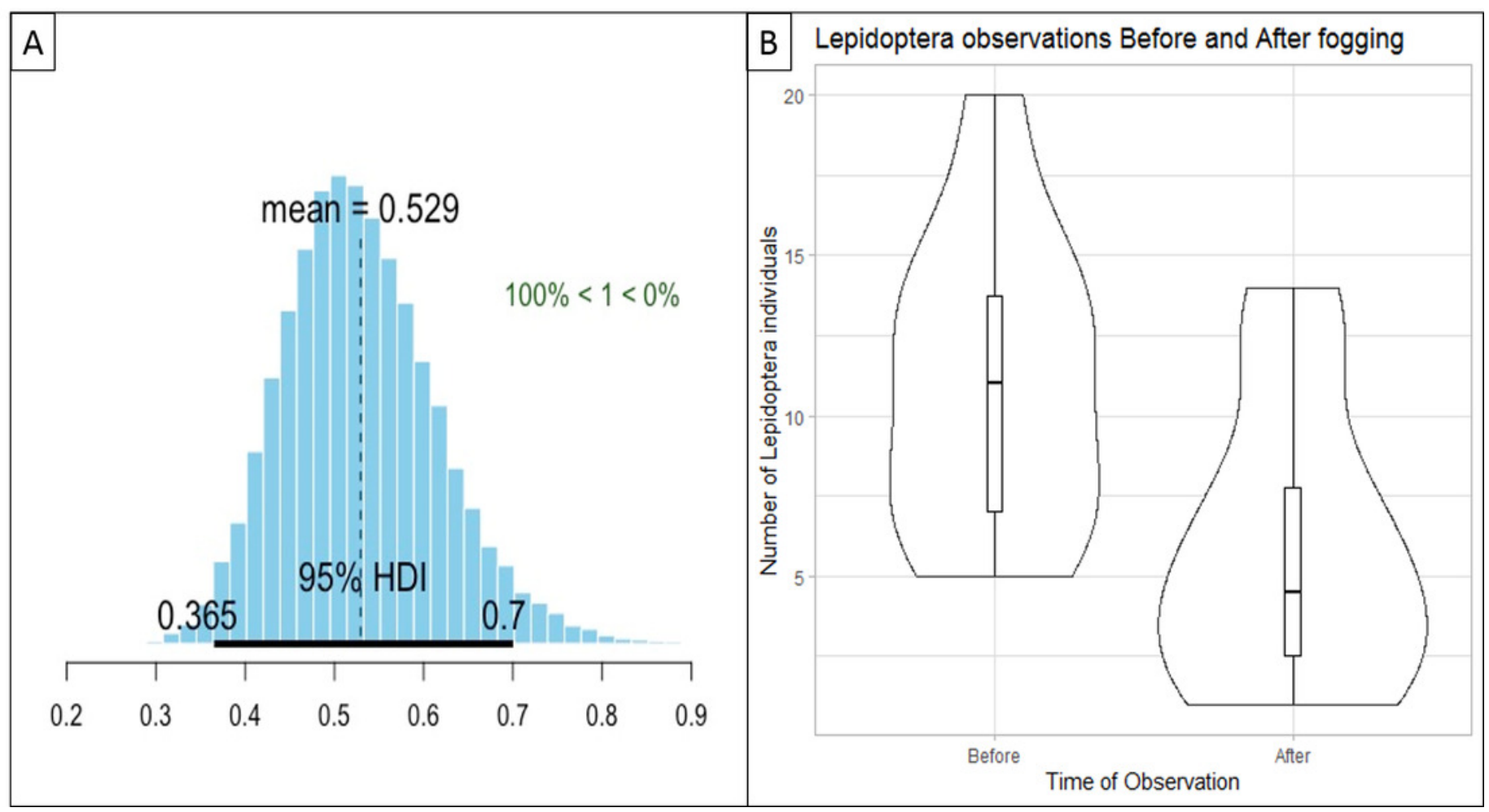

